\title{
Negotiated Peace in Afghanistan Is a Complex, but Feasible Goal
}

\author{
FOR RELEASE
}

Wednesday

August 17, 2011

A sustained focus on Afghanistan at all levels of the U.S. government is needed for the United States to make the most of its limited influence on the complex Afghan peace process, according to a new study from the RAND Corporation.

"The main goal from the United States' perspective is to prevent Afghanistan from becoming a haven for, and an ally to, transnational terrorists," said James Dobbins, co-author of the study and a senior fellow at RAND, a nonprofit research organization. "Afghanistan has been fought over for hundreds of years because it is of strategic interest to many nations, and hammering out a peace agreement with so many varying interests and objectives is likely to prove difficult."

Both the Afghanistan and U.S. governments are in favor of a negotiated peace that would give the Taliban some role in a future government. Such an approach also has been endorsed by NATO and most of Afghanistan's neighbors.

"We believe there is enough of a confluence of interest on the part of the major parties to the war in Afghanistan to make a negotiated settlement feasible and worth pursuing," said James Shinn, study co-author and a lecturer at Princeton University.

"There are many obstacles, and the process will probably require years of talking during which fighting will continue and even intensify," he said. "Negotiation does not represent an easy or early way out of Afghanistan for the United States and its NATO allies, but it is the only way in which this war is likely to end."

Dobbins served as the lead negotiator for the United States at the Bonn Accords that established Afghanistan's current government in 2001. Shinn is a former assistant secretary of defense for Asia and was one of the authors of the Bush administration's Afghan Strategy Review.

Based on a year of field work and interviews, including meetings with current and former Taliban fighters in Afghanistan and Pakistan, the study outlines the goals, attitudes and motivating factors of the principal parties to an Afghan peace treaty. It includes a discussion of the role and influence of other nations with an interest in the outcome, particularly Pakistan, India, and Iran.

The researchers also dissect the likely obstacles to any agreement and outline how formal negotiations might be best structured. 
The United States and its NATO allies are under pressure to get serious negotiations underway. But as one of the main protagonists in the conflict, the United States is not in a position to launch and then orchestrate the kind of multi-layered process that will result in a durable agreement, according to the report. A trusted, neutral facilitator, possibly under United Nations auspices, will be needed to get the process underway.

Shinn and Dobbins discuss what the terms of a peace accord likely would include, from security, governance and trade agreements to positions on terrorism and narcotics trafficking. The United States should not be drawn into a discussion of Afghanistan's social or constitutional issues, unless those issues would affect the primary goal.

While a peace accord is possible and worth pursuing, it is by no means certain. The report suggests that the United States should prepare for two futures — one negotiated and the other not - and stay focused on the goal of keeping Afghanistan from falling to an al Qaeda-linked regime.

The study, "Afghan Peace Talks: a Primer," can be found on www.rand.org.

Funding for this study was provided by RAND's Investment in People and Ideas program, which combines philanthropic contributions from individuals, foundations and private-sector firms with earnings from RAND's endowment and operations to support research on issues that reach beyond the scope of traditional client sponsorship.

The study was conducted within the RAND National Security Research Division. The division conducts research and analysis on defense and national security topics for the U.S. and allied defense, foreign policy homeland security and intelligence communities and foundations and other non-governmental organizations that support defense and national security analysis. 